\title{
Paideusis
}

\section{Listening from Silence: Inner Composure and Engagement}

\section{Leonard J. Waks}

Volume 17, Number 2, 2008

URI: https://id.erudit.org/iderudit/1072431ar

DOI: https://doi.org/10.7202/1072431ar

See table of contents

Publisher(s)

Canadian Philosophy of Education Society

ISSN

0838-4517 (print)

1916-0348 (digital)

Explore this journal

Cite this article

Waks, L. (2008). Listening from Silence: Inner Composure and Engagement. Paideusis, 17(2), 65-74. https://doi.org/10.7202/1072431ar
Article abstract

The Indian-America philosopher Sri Chinmoy Ghose has distinguished between outer silence, inner silence, and innermost silence. In this paper I explore these distinctions and their educational relevance. My main conclusions are that (a) a deep inner silence, undistracted by questions or other thoughts, is at the root of one paradigm kind of good listening in education, and (b) what Chinmoy refers to as "innermost silence" is the moral virtue of receptivity to others that sustains inner silence, even under challenging conditions, a virtue of importance in teaching and in learning from others.
This document is protected by copyright law. Use of the services of Erudit (including reproduction) is subject to its terms and conditions, which can be viewed online.

https://apropos.erudit.org/en/users/policy-on-use/ 


\title{
Listening from Silence: Inner Composure and Engagement
}

\author{
LEONARD J. WAKS \\ Temple University, USA
}

The Indian-America philosopher Sri Chinmoy Ghose has distinguished between outer silence, inner silence, and innermost silence. In this paper I explore these distinctions and their educational relevance. My main conclusions are that (a) a deep inner silence, undistracted by questions or other thoughts, is at the root of one paradigm kind of good listening in education, and (b) what Chinmoy refers to as "innermost silence" is the moral virtue of receptivity to others that sustains inner silence, even under challenging conditions, a virtue of importance in teaching and in learning from others.

\section{Introduction}

The British poet Alan Spence, in a recent BBC talk, notes that "maintaining even an outer silencekeeping our mouths shut-is more difficult than we might imagine. Much more difficult is maintaining an inner silence-the absence of thought." Spence (2004) complicates matters, quoting the Indianborn philosopher and teacher Sri Chinmoy Kumar Ghose (1931-2007) who speaks of an "innermost silence" beyond inner silence. "The human mind is full of questions," Chinmoy says, but only this innermost silence, which is "receptivity itself, our capacity to be still, to be open, to simply listen," has, or is, the answer. ${ }^{1}$

In this paper I explore these distinctions between outer, inner, and innermost silence and their relevance for listening in educational contexts. My main conclusions are that: (a) a deep inner silence, undistracted by questions or other thoughts, is at the root of one paradigmatic kind of good listening that has an important though not exclusive place in educational encounters, and, (b) what Chinmoy refers to as "innermost silence" is the moral virtue of receptivity that sustains openness to others even under challenging conditions, a virtue of prime importance in teaching. I devote sections I and II of my paper to outer and inner silence, and section III to this elusive notion of "innermost silence." I begin by situating the discussion in recent work on listening in education.

Listening was until recently a neglected concept in educational philosophy and theory; somewhat lost among numerous discussions of teaching, training, learning, understanding, indoctrinating, goals and objectives, cultures and identities, and other topics. This is somewhat surprising, as school and college students spend most of their time listening to teachers, and, to a lesser extent, to one another.

\footnotetext{
${ }^{1}$ See Spence, 2004. Spence is among the many world-wide students of Chinmoy, a philosopher-sage nominated for the Nobel Peace Prize by Desmond Tutu and Mikhail Gorbachev; Chinmoy counted Nelson Mandela and Al Gore among his friends. His New York Times obituary is available in Kilgannon, 2007.

(C) Copyright 2008. The author, Leonard J. Waks, assigns to Paideusis the right of first publication and educational and non-profit institutions a non-exclusive license to use this document for personal use and in courses of instruction provided that the article is used in full and this copyright statement is reproduced. Any other usage is probibited without the express permission of the author.
} 
Scholars might have, but did not, attend to listening in relation to these other notions; for example, to students' listening to teacher talk or the talk of other students with different cultural identities.

This situation changed dramatically after Sophie Haroutunian-Gordon (2003) delivered her presidential address to the Philosophy of Education Society (US) on "Preparing to Turn the Soul: Toward a Philosophy of Listening in a Democratic Society." In that address Haroutunian-Gordon presented a set of "hypotheses" about conditions under which people will listen to speakers with a different perspective. Listeners will listen, she hypothesized, when speakers address questions listeners actively entertain. Listening is itself a kind of questioning, she claims, because listeners, in attending to speakers' utterances, question the truth or adequacy of the speakers' ideas and their own.

Haroutunian-Gordon's notion of listening as questioning or as active cognitive processing has subsequently been questioned. I have distinguished two types of interpersonal listening (Waks, 2004). Appropriating terms from religious contemplation, I have labeled these cataphatic and apophatic, the former kind of listening consciously employs pre-determined categories actively to interpret a speakers' utterances, while the latter sets these categories aside in order to perceive the utterances in a fresh and immediate manner. I argued that cataphatic listening, the type analyzed by Haroutunian-Gordon, is typically and correctly depended upon in standard teaching-learning routines: for example, when a teacher listens to oral reading performances of students to assign them to ability groups on the basis of reading accuracy and fluency. Many educational encounters, however, call for apophatic listening, because when students deviate from routine and expected patterns, teachers and other students have to set aside pre-determined categories and listen in a direct and open manner. ${ }^{2}$ Haroutunian-Gordon (2007) has denied the validity of this distinction, insisting that all listening is cataphatic as it depends upon listeners' employment of interpretive categories. She forcefully raises the question how direct listening unmediated by interpretive categories is even possible. This paper is intended to answer that question.

\section{Outer Silence: A Quiet Mouth}

Consider two familiar cases of interpersonal listening. Case (i): a group of scholars sits in a noisy dining room at a conference center, and despite their best efforts, they can hardly make out what the person across the table from them is saying. Case (ii): at the same table one participant is asking another to elaborate on a point in his just-presented conference talk. But after the speaker utters just a few sentences the first participant, the one asking for elaboration, begins to raise questions. ${ }^{3}$ And before the speaker can adequately answer these, the participant asks still further questions. The listener's questions distract and deflect the speaker; she does not get to say what she intends, or what she might think to say on-the- spot, and neither putative listeners nor the rest of us get to hear her. ${ }^{4}$ In this case, the distracting noise comes not from the background but from the questioner himself.

Of course, "active" listening characterized by outer questioning is not always just distracting noise. A skillful interviewer, in contrast with a restless questioner, can sometimes effectively bring out deeper levels of meaning by raising questions. The meanings disclosed even by skillful questioning are nonetheless influenced by not only the speaker but also the questioner; the questions affect what the speaker says and how he says it, and also what he does not say but would have said if not deflected.

\footnotetext{
2 Jim Garrison (2005) and Michel \&Wortham (2007) have subsequently used this distinction between cataphatic and apophatic listening to discuss compassionate listening and listening in innovative institutional contexts respectively.

${ }^{3}$ I focus on examples of questioning to tie my ideas to the discussion of Haroutunian-Gordon's hypotheses. Similar remarks would apply to other forms of conscious rational thinking.

${ }^{4}$ To avoid gender bias I will use 'he' or 'she' interchangeably in contexts where I require the third person singular.
} 
A deeper point is that even the skillful questioner, by adopting an active, critical questioning mind-set, by receiving the speaker's utterances with a mind to raising questions, inevitably selects out, or focuses upon, or attends to, certain meanings from among all of those expressed by the speaker, and ignores others. I will develop this point further in the next section.

\section{Inner Silence: A Quiet Mind}

\section{Sealing Your Lips May Not Be Enough}

Maintaining outer silence is not always sufficient to counter the negative impact on listening created by the restless external questioner in case (ii). To counter it, listeners may need to refrain not merely from asking questions out loud, and thus distracting speakers and obscuring their meanings, but also from entertaining inner questions and other thoughts that distract themselves as listeners from the speaker's intent, (and may subtly influence the speaker as well). That is, if listeners seek to grasp speakers' full intent, they will do well to maintain an inner silence.

Let us now consider case (iii). At the same conference dinner another participant is listening to the same conversation described in case (ii), but instead of posing her questions to the speaker, she instead listens in external silence, raising questions only in her own mind. Building upon the point made earlier about the distractions inherent in the questioning mind-set, it makes little difference to her listening whether she is raising questions externally or internally. Her consciousness can not be in two places at the same time; to the extent that she is actively forming and formulating questions about what is said, whether these questions are openly stated or silently considered, whether voluntarily or automatically generated, she is attending away from the speaker and his intent.

This point is not specific to questions alone; it is quite general with respect to any explicit thoughts arising in the listeners mind. Deep listening requires a quiet mind.

\section{Questioning and Consciousness}

This notion of attending invites some rough and ready consideration of the nature of an attending consciousness. The world of experience is full of potential meanings, a very great many of which occur in parallel and all of which become available to the subject at any given time. The subject's long term memory and cognitive processing capabilities also work in parallel. Conscious attention, however, focuses the subject. It picks out meanings, one at time, for close observation or rational processing or other purposes, whether from pre-consciousness or from the world.. Speaking in the language of Gestalt psychology, I would say that conscious awareness takes the form of well-formed figures upon a ground. An object of focus (which of course can be a pattern of related components) dominates consciousness and all else recedes.

We are all familiar with the famous thought experiments involving the duck/rabbit or the young woman/old hag. When the first element in each set presents itself as figure, the other recedes instantly as ground. When the gestalt reverses, and the figure and ground shift positions, the initial figure disappears into the ground. We cannot be conscious of the first (the duck or young woman) and the second (the rabbit, the hag) at the same time. Or consider any short list of items one has memorized: for example, the Ten Commandments or the seven wonders of the ancient world. One serially calls the first to mind, then the second and so on, effortlessly. But nonetheless one cannot hold any two of them in mind at the same time (try it!). Consciousness is a serial processor. ${ }^{5}$

\footnotetext{
5 "Consciousness focuses us. If time is nature's way of keeping everything from happening at once, then consciousness is nature's way of keeping everything at once” (Myers, 2002, p. 24).
} 
In like manner, in listening, the "figure" of a speaker's utterance cannot co-exist with a "figure" of questions arising for verbal formulation in the inner milieu. The entertaining of questions or other thoughts in consciousness inevitably pushes the speaker's utterance into the background. Only one item can take the stage of consciousness at any given time.

Of course, consciousness is fluid; external utterances and inner thoughts may rapidly alternate as figures in the ebb and flow of listening, and listeners' minds may fill in the empty spaces created when inner contents block out the outer contents. This is easily demonstrated in the gestalt experiment of an image of a spoon with a segment erased from the handle. When the picture is presented at a certain distance from the observer, the observer's mind simply completes the image by filling in the missing segment. ${ }^{6}$ While this sort of filling-in process may enable listeners attending to inner questions to construct continuous meaning in a speaker's utterances, it is not always the speaker's meaning. To a certain extent listeners, by filling in empty spaces in the utterance, hear what they imagine is said.

\section{Momentary Stillness and Preconscious Readiness}

Even a mind momentarily devoid of thoughts is not necessarily altogether quiet or still. When no thoughts arise as well-formed figures in consciousness, there is nonetheless typically a pre-conscious ground of readiness for semantic associations. The pre-conscious mind may be loaded even when it isn't firing, and thoughts and feelings may be triggered into consciousness or amplified in the wings of consciousness; a speaker's utterances may activate such associations in a previously quiet mind, bringing conscious thoughts to the fore or generating subtle shifts in background mood, etc. Just as the external setting of a conversation constitutes an atmosphere that affects what is said and what it is taken to mean, so the internal atmosphere-the listeners' mental set or pre-organized readiness-also affects what they hear and even subtly influences what speakers say.

These internal atmospherics of communication can sometimes be effectively manipulated by controlling the external atmosphere. For example, calming background music, or white noise, may be introduced intentionally to distract the speaker or listener from either semantically charged background noises or preconscious thoughts and feelings that might in turn distract from what is said or heard.

\section{Total Absorption}

Even when listeners' minds are not attending to any thoughts or questions, then, a proprioceptive ground, a mood, a somatic ground, affected by the preconscious readiness of the listeners, may persist. The listener remains self-conscious, aware of self. So we might say that the inner milieu remains not altogether still. To understand this more clearly, consider case (iv): a meditation teacher directs his student to concentrate first on the breath only, casting out all other thoughts, and finally even to let go of the thought of breathing, so that only breathing itself remains. ${ }^{7}$ This merging of the student with breathing or becoming one with it, suggests a quite different form of consciousness than self-conscious attention, as it involves letting go of both the category "breathing" and of the breathing "self."

A student of breath meditation first attempts to attend to breathing, but her thoughts fly around and catch hold, so that she finds herself thinking and not attending to her breathing, which in turn has faded into the pre-conscious ground. She reminds herself to attend to breathing but thoughts continue to intrude. The teacher advises: "let these thoughts come and go, but don't let them catch hold. Detach from them; don't identify with them. Let them arise, but don't get behind them and think them yourself." If the student succeeds, then the random thoughts recede and the ebb and flow of breath becomes the sole figure against the proprioceptive ground. The student then experiences herself-as-breathing. But then the proprioceptive ground, or self-consciousness itself, may fade away. There is then no experienced

${ }^{6}$ This diagram is provided and discussed in Gigerenzer, 2007, p. 41.

${ }^{7}$ A comment on a Zen story found on psychologist John Suler's website Zen stories to tell your neighbors. 
sense at all of a center of consciousness, a controlling center of self, or of embodiment. Now she experiences just breathing, not herself breathing. Her self is totally absorbed in breathing.

For readers who have not practiced meditation or experimented with alternative states of consciousness, imagining this experience may require quite a stretch. Fortunately one does not have to go so far afield to take note of experiences of this sort.

Consider case (v): a man comes home after a stressful day at work, has a small glass of wine, and listens to a classical CD through a headset. At first he has difficulty tuning in to the music, because he is aware of stressful feelings and cannot clear his mind of thoughts about the day's events. Later he relaxes somewhat and the thoughts and feelings fade away and he tunes into the music, though he can still sense at the periphery of consciousness a persisting mood. Finally he becomes so totally absorbed in the music that he forgets himself entirely. This case provides at least one paradigm example of good listening. It may be a rare and wonderful experience, but it is by no means unheard of.

What happens when the music ends? Listeners are frequently shocked into a sudden awareness of themselves, as a mood or state of self-consciousness returns and thoughts and feelings then rush in to consciousness to fill the void. But is it not possible that after the music recedes only a void remains, and, as Sri Chinmoy puts it, listeners find themselves entirely immersed in a "sea of silence"? Such would be the limit case of inner silence or quiet mind. The mind would in that case be a frictionless intake device, a clear channel without an immediate input. Meditation techniques exist to induce this experience: for example., concentrating on a vibrating string or bell and following it as it gradually returns to quiet, taking the listener along with it. ${ }^{8}$

\section{Total Absorption and Words}

The skeptical reader may now ask whether such a self-forgetting silence can really serve as the ground for good verbal listening. How can listeners attend to speakers and their utterances without positioning themselves, with their interests and interpretive categories, in the scene of listening?

There is a very strong bias in favor of conscious, rational cognitive processing in Western thought. Plato assigns to the rational function of the soul the job of governor over the spirited and vegetative functions. Descartes places rational thought at the center of human existence: "Cogito, ergo sum." Philosophy classes are training sessions in critical thinking: critical reading and critical listening. It is taken more or less for granted that good reading or listening involves critical questioning, in which passages are analyzed into component terms and propositions, into premises and conclusions, which are in turn analyzed for plausibility or truth or inferential validity. If recipients are not parsing texts in such a manner, it seems natural to ask how they can even claim to understand them, much less assess their value?

A skeptic might reluctantly grant that music, being non-verbal, could in some way be absorbed directly and yet well by such a quiet, purely receptive mind. But the skeptic will question whether it is possible for verbal phenomena, passages of text or speakers' utterances, to be absorbed or grasped directly, without interpretation. I believe that this kind of direct understanding is possible, and though I can hardly claim to prove it I can offer examples which support this possibility.

Some famous split brain experiments demonstrate that verbal phenomena can sometimes get from the world to certain selves without the mediation even of explicit conscious awareness. It is widely known that the two cerebral hemispheres have different processing capabilities, and that robust human perception and action typically involve their moment to moment coordination. But experiments have shown that when epilepsy patients have their cerebral hemispheres severed, this coordination is no longer possible. The patients end up with two uncoordinated brains; they are literally of two minds.

The wiring diagram of the visual cortex allows experimenters to present information to these separate sides of the brain in order to determine how subjects respond. David Myers (2002) reports that

${ }^{8}$ The technique is found in the classic Vijanabhairava Tantra (see Michaels and Johnson, 2006). 
in one experiment, the psychologist Michael Gazzaniga showed these split brain patients a large sign with the word $\mathrm{HE} *$ ART written on it, in an apparatus that allowed HE to appear in the left visual field (from which sensations are transmitted to the right, non-verbal brain), and ART to appear in the right visual field (from which it was transmitted to the left, verbal brain). Gazzaniga then placed cards with the words HE and ART in front of the subjects and asked them to say out loud, and at the same time point to, what they had seen in the experimental apparatus. The patients said they had seen ART, and it startled them to see themselves pointing to HE with their left hands (controlled by the right brain). The left hand pointed correctly to what the subject had seen but had no awareness of seeing.

In another experiment, a picture of a spoon was presented to the left visual field and thus transmitted to the right, non-verbal brain. The patients were then asked what they had seen in the picture and they reported verbally that they were not conscious of seeing anything. Yet they were able without effort to pick out a spoon from among a group of objects hidden from view by a black cloth. As in the previous case, they were startled, asking "how could I possibly pick out the right object, when I don't know what I saw?" As David Myers puts it, "the left brain (is) bewildered by what its non-verbal right brain quietly knows." 9

\section{Absorbing Words As Others Absorb Music}

Fortunately, there are many examples of mental "by-pass" phenomena involving listeners with bealthy brains. A person in a forest reacts emotionally to the sound of rustling leaves even before consciously hearing it. This happens because the sounds are transmitted from the auditory sensors to the thalamus (the sensory switching circuit), which projects them directly to both the amygdala (a pair of emotion control centers in the brain core) and the auditory cortex, but the direct pathway to the amygdala is shorter. As Myers (p. 37) explains, "the eye-to-amygdala pathway which by-passes the cortex enables an emotional response before the intellect intervenes." A similar neural by-pass may enable pre-cortical reception as a component of the emotional response to music. ${ }^{10}$

As a result of the thalamus-to-cortex pathways, however, conscious attention intervenes in listening, and if it detects a need for close observation or cognitive appraisal then thinking tends to take over, damping emotional response. This may explain why total absorption in music in deep inner silence is so satisfying; thinking has not been permitted to dampen the essential emotional aspects of the listening experience.

Turning to verbal listening, we must consider whether there might be neural by-pass pathways projecting speech directly through consciousness, as a frictionless throughput device, to right brain centers of pre-conscious higher order cognitive processing, without engaging conscious thinking.

There is no a priori reason for denying this possibility, and a striking case suggests that something like this actually happens. Consider case (vi): William Shawn of The New Yorker, arguably the greatest acquisition editor in magazine history, was famous for his listening skills. Calvin Trilling said that when Shawn listened he just "shook his head in wonderment ... but when he responded, it was clear that he had absorbed everything said, every fact, every allusion, every nuance." Brendan Gill said that Shawn's listening was a "gnomic minimalism" but "writers became so attached to Shawn (because) he seemed to understand what they were doing as no one else in their lives ever had" (Yagoda, p. 331). Ved Mehta said "I had never before had anyone in my life listen to me at as deep a level as he was doing, with no wish to judge-with only boundless interest and curiosity. He seemed to listen with childlike wonder, his gaze so steady and penetrating that I felt he was looking straight into my soul." "Most people in

\footnotetext{
${ }^{9}$ Myers, 2002, p. 19

10 The psychologist John Bargh has demonstrated that people make evaluations of what they see in less than a quarter of a second. "In the blink of an eye, before engaging any rational thought, we find ourselves loathing or liking a piece of abstract art, a Doberman, or a neighbor" (see Myers, 2002, p. 33)
} 
conversation ... had their own preconceptions or agendas," Mehta added, but (and here is the clincher) "in contrast, he [Shawn] seemed to absorb words as a musician absorbs music" (Yagoda, p. 322, my emphasis).

The direct receptivity illustrated in this case may frequently be demonstrably better than listening involving conscious processing. Let us consider some additional cases. People labeled "idiot savants," though typically exhibiting poor intellectual capabilities, can nonetheless demonstrate amazing intuitive mental capabilities. They seem to move from problem input to solution output without conscious mediation. Musical savants can reproduce any music they have ever heard, or identify any brief musical passage as coming from any of over two thousand operas; mnemonic savants can memorize long sequences of nonsense syllables or numbers and remember them for life, calculating savants can say exactly what day of the week any past or future date falls on, etc. When asked how they do it, some simply say they don't know, while some others say they are just "geniuses."

My school classmate Dave was certainly no idiot, but he was something of a savant. Dave was able automatically and accurately to perform any arithmetic operation. Asked to multiply or divide large numbers Dave could provide an instant answer. He didn't know how he did it, and remained somewhat surprised that he always seemed to get the right answer. Our teachers quickly realized that it didn't work to put arithmetic problems on the blackboard and ask us to raise our hands when we had the answer, because Dave had his hand up almost before the question was written. Instead of thinking about the problem, Dave appeared to channel it directly to an internal calculator. We are not at all amazed that a simple calculator from a dollar store can do exactly what Dave did, but we are amazed that Dave, with his much more complex wiring, could. Maybe more of us could do things like this if we simply learned to by-pass our conscious rational thinking and permit pre-conscious processes to operate. Interestingly, Dave was no better at explicitly calculating answers than the rest of us.

\section{The Advantage of Direct over Cognitively Mediated Listening}

The argument so far has been aimed to support the possibility of direct listening unmediated by explicit conscious mental processing. Now I want to argue that in many situations, including some of the most important for human well-being and education, pre-conscious intelligence actually works demonstrably better than conscious thinking.

The psychologist Tim Wilson has developed a "Dual Attitude" theory, postulating that mental processes that control our behavior are frequently distinct from those that we use to explain and rationalize behavior: that is, gut feelings typically guide behavior while rational thinking makes sense of it after the fact. Wilson has demonstrated this phenomenon in several ways. Here are two:

(a) Wilson asked couples to say how happy they were with each other. Their answers predicted whether they would still be dating six months later. But when he asked them first to detail the reasons why their relationships were, or were not, making them happy, and then asked how happy they were, their answers had no predictive power.

(b) Wilson showed subjects art posters and asked them to pick one to keep. He then asked others to say why they liked or disliked the posters before selecting one to keep. A few weeks later the subjects in the first group remained satisfied with the posters they had chosen, while the subjects in the second group were significantly less satisfied (see Myers, 2002, p. 33-34).

In both cases, conscious thinking proved demonstrably less valid than direct, unthinking choice. Rational analysis appears to have focused conscious attention upon readily verbalized aspects of the situation that were relatively less important for judgment than the relevant emotional aspects that are harder to put into words and that conscious thinking occluded (Myers, 2002, pp. 34-5). In like manner, the open, holistic or apophatic listening of an editor like Shawn may yield greater understanding of verbal nuances than consciously focused critical listening. ${ }^{11}$

11 "Although the left brain is adept at literal interpretation of language, the right brain excels in making subtle inferences.... As one patient explained after suffering right brain stroke damage, 'I understand words but I'm 
Similarly, in classroom situations where teachers contend with creative or deviant behaviors, where teachers' pre-determined categories and routine responses are unlikely to be adequate, direct and open listening to students may enable teachers to tune into significant features of the expression that would be filtered out in explicit, rational critical listening. In such cases we might expect school students, like Shawn's New Yorker writers, to sense that they have been "really heard," and to feel an emotional rush combining profound appreciation and enhanced self-esteem.

\section{Innermost Silence: A Quiet Self}

Deep listening is inherently moral. Listening to others so as to hear their full intent rather than to gain useful information from them is a paradigm of treating others not merely as means but as ends-inthemselves.

The unusual examples of inner silence above (breath without a breather, music without a listener) can be induced by hypnosis or mind control techniques in all sorts of people, regardless of their underlying character. In themselves, these experiences have no more moral significance than magic tricks. Even violent, lustful, greedy, cowardly or foolhardy people may, with the aid of such techniques, attain trance states of deep inner silence. ${ }^{12}$

But making oneself available to another, allowing the intent of the other fully to enter one's inner milieu, involves great risk. The other may share experiences and disclose realities which take the listener beyond his innocent, self-protecting understanding and may be profoundly unsettling. Few among us would willingly take into our own inner experience, for example, the blood thirsts of mass murderers or the horror of terror victims. Even ordinary looking people, moreover, sometimes reveal themselves as unbelievably different or weird, so it is hardly surprising that so many people remain closed and distant.

An ethics of virtue, however, would offer special praise to people who have gained a high degree of self-control, who have tamed their emotional demands for security, comfort, and control. Think of those who have consistently displayed extraordinary courage in the face not just of vicarious horror but the real thing: Gandhi, Mandela, Mother Theresa, and the Vietnamese monks who immolated themselves to give witness to moral evil. They demonstrate a quiet self, not just a quiet mind. They have transcended their ego selves; they have nothing of this sort left to protect, so there is nothing so dangerous that they cannot open themselves to experience it. Although such people invariably retain traces of individual personality, their individual existence has somehow loosened its grip and relaxed its claim upon them. In their "innermost silence" they no longer cry "me, me, me!" Things can come and go both in the external world and the inner milieu, without their getting caught up by emotional reactions or restless thoughts.

Many popular books emphasize the extraordinary experiences and supernatural powers of gurus, yogis, shamans, and the like. Such books appeal to the emotional longings for the transcendent in our secular modern world, but they pay insufficient attention to the extraordinarily demanding aspects of the spiritual training programs these individuals have undergone. In Zen monasteries, for example, the hours are long; the meditation halls are cold; the mental demands are exhausting; the physical positions

missing the subtleties.' Thus the right brain helps us modulate our speech to make meaning clear" (Myers, 2002, p. 20).

12 In traditional Buddhism two kinds of meditation experience, samatha and vipassana, are distinguished. The former term may be translated as "tranquility" and refers to methods for promoting mental concentration or absorption. The latter may be translated as "clear seeing" or "insight" and refers to deep grasp of the roots of the mental contaminations that cause attachment and suffering. Concentration or absorption is conceived as a necessary prerequisite for, but distinct from, insight, just as clear eyeglasses are a prerequisite to, but distinct from, visual discernment. The emptiness of a still mind, free from mental contents or a sense of self, is thus distinguished from the deep emptiness or sunyata that results from insight, and does not lie on the level of mere mental stillness or concentration (Nayayon, n.d.) 
are painful; the food is almost inedible; the authority hierarchy and moral rules are rigid and absolute. Narcissistic demands are simply beaten out of practitioners. The eventual virtues of the practitioners derive from the long and unforgiving moral training they voluntarily subject themselves to, rather than any extraordinary experiences they undergo or psychic powers they attain.

What we have discussed in section II as "inner silence" and what we are now calling "innermost" silence are distinct. Neither is strictly a necessary nor sufficient condition of the other, though of course inner silence is an important enabling condition for the mental clarity demanded in self understanding and change. Innermost silence is not merely a persisting or deep inner silence in experience, but rather a profound moral virtue. It is, recalling Sri Chinmoy's words, "receptivity itself, our capacity to be still, to be open, to simply listen." Consider this from Sri Aurobindo (Letters on Yoga, p. 581):

\footnotetext{
In the calm mind it is the substance of the mental being that is still ... if thoughts or activities come, they cross the mind as a flight of birds crosses the sky in a windless air. It passes, disturbs nothing, leaving no trace. Even if a thousand images or the most violent events pass across it, the calm stillness remains as if the very texture of the mind were a substance of eternal and indestructible peace. (emphasis added)
}

The eternal peace Aurobindo refers to is hardly a retreat from the field of moral action. Rather, as Aurobindo concludes: "a mind that has achieved this calmness can begin to act even intensely and powerfully, but it will keep its fundamental stillness." And Sri Chinmoy agrees, calling innermost silence "the blossoming of our indomitable inner will." The close connection between innermost silence as freedom from attachment, listening directly to others, and indomitable will in moral action can be observed in the lives of Gandhi, Mandela, Mother Theresa and others, but a philosophical examination of this connection will have to wait for another paper.

\section{References}

Aurobindo (Sri Aurobindo Ghose) (1969). Letters on yoga, volume I. Pondicherry India: Sri Aurobindo Ashram Publications.

Garrison, J. (2005). Compassionate, spiritual, and creative listening in teaching and learning. Teaching and Learning. 31(3 \& 4), 28-34.

Gigerenzer, G (2007). Gut feelings: The intelligence of the unconscious. New York: Viking.

Haroutunian-Gordon, S. (2003, March). Preparing to Turn the Soul: Toward a Pbilosophy of Listening in a Democratic Society. Presidential Address, 59 th Annual meeting of the Philosophy of Education Society, Miami Beach FL.

Haroutunian-Gordon, S. (2007) Listening and Questioning, Learning Inquiry 1(2), 143-152.

Kilgannon, C. (2007, October 13). Sri Chinmoy, athletic spiritual leader, dies at 76. The New York Times, October 13. Retrieved June 3, 2007, from http://www.nytimes.com/2007/10/13/nyregion/ 13chinmoy.html.

Michel, A. \& Wortham, S. (2007) Listening beyond the self: How organizations create direct involvement, Learning Inquiry 1(2), 89-97.

Michaels, M. and P. Johnson (2006). The spiritual power of silence and listening. Retrieved October 10, 2008 from http://www.chronogram.com/issue/2006/08/wholeliving/innervision.php

Myers, D. (2002) Intuition: Its powers and perils. New Haven, CT: Yale University Press.

Nanayon, U. K. (n.d.). Reading the mind, (T. Bhikkhu, Trans.). Retreived October 10, 2008 from http://www.accesstoinsight.org/lib/thai/kee/readmind.html\#void

Spence, A. (2004). Reflections on meditation. Retrieved June 3, 2007 from http://www.bbc.co.uk/religion/ religions/hinduism/ritesrituals/meditation_1.shtml 
Suler, J. (1999) Zen stories to tell your neighbors. Retrieved June 3, 2007 from http://users.rider.edu/ $\sim$ suler/zenstory/silence.html

Waks, L. (2004). Two types of interpersonal listening, annual meeting of the American Educational Research Association, (forthcoming in Teachers College Record).

Waks, L. (2007). Listening and questioning: the apophatic/cataphatic distinction revisited, Learning Inquiry, 1(2), 153-161.

\section{About the Author}

Leonard J. Waks is professor (emeritus) of educational leadership and policy studies at Temple University, Philadelphia USA. He earned a Ph.D. in philosophy at the University of Wisconsin (Madison). He taught ethics and social philosophy at Purdue and Stanford before joining the education faculty at Temple in 1971, and retired in 2005. Waks is the author of numerous scholarly articles and book chapters as well as the book Technology's School (JAI, 1995). He recently edited Leaders in Philosophy of Education: Intellectual Self-Portraits (Sense, 2008). His current research focuses on the educational arrangements emerging in global network society. Email: ljwaks@yahoo.com 